\title{
The relationship between members of the canonical NF-KB pathway, components of tumour microenvironment and survival in patients with invasive ductal breast cancer
}

\author{
Lindsay Bennett' ${ }^{1,3}$, Elizabeth A. Mallon ${ }^{2}$, Paul G. Horgan ${ }^{3}$, Andrew Paul ${ }^{4}$, Donald C. \\ McMillan ${ }^{3}$ and Joanne Edwards ${ }^{1}$ \\ ${ }^{1}$ Wolfson Wohl Cancer Research Centre, Institute of Cancer Sciences, College of Medical, Veterinary and Life Sciences, \\ University of Glasgow, Glasgow, Scotland, United Kingdom \\ ${ }^{2}$ Department of Pathology, Queen Elizabeth University Hospital, Glasgow, Scotland, United Kingdom \\ ${ }^{3}$ Academic Unit of Surgery, School of Medicine, University of Glasgow, Glasgow Royal Infirmary, Glasgow, Scotland, United \\ Kingdom \\ ${ }^{4}$ Strathclyde Institute of Pharmacy and Biomedical Sciences, University of Strathclyde, Glasgow, Scotland, United Kingdom \\ Correspondence to: Joanne Edwards, email: joanne.edwards@glasgow.ac.uk \\ Keywords: breast cancer, NF-KB, tumour microenvironment, survival \\ Received: November 17, $2016 \quad$ Accepted: February 12, $2017 \quad$ Published: March 09, 2017 \\ Copyright: Bennett et al. This is an open-access article distributed under the terms of the Creative Commons Attribution License (CC-BY), \\ which permits unrestricted use, distribution, and reproduction in any medium, provided the original author and source are credited.
}

\section{ABSTRACT}

The aim of the present study was to examine the relationship between tumour NF-KB activation, tumour microenvironment including local inflammatory response (LIR) and cancer-specific survival in patients with operable ductal breast cancer.

Immunohistochemistry (tissue microarray of $\mathbf{3 7 6}$ patients) and western blotting (MCF7 and MDA-MB-231 breast cancer cells) was performed to assess expression of key members of the canonical NF-KB pathway (inhibitory kappa B kinase (IKKB) and phosphorylated p65 Ser-536 (p-p65)). Following silencing of IKK $\beta$, cell viability and apoptosis was assessed in both MCF7 and MDA-MB-231 cell lines.

$P-p 65$ was associated with cancer-specific survival (CSS) (nuclear $P=0.042$ and total $P=0.025)$. High total $p-p 65$ was associated with increase grade tumour grade $(P=0.010)$, ER positivity $(P=0.023)$, molecular subtype $(P=0.005)$, lower KlintrupMakinen grade $(P=0.013)$ and decreased $C D 138$ count $(P=0.032)$. On multivariate analysis, total p-p65 expression independently associated with poorer CSS $(P=0.020)$. In vitro work demonstrated that the canonical NF-KB pathway was inducible by exposure to TNFa in ER-positive MCF7 cells and to a lesser extent in ER-negative MDAMB-231 cells. Reduction of IKK $\beta$ expression by siRNA transfection increased levels of apoptosis and reduced cell viability in both MCF7 $(P=<0.001, P=<0.001$, respectively) and MDA-MB-231 cells $(P=>0.001, P=0.002$, respectively). This is consistent with the hypothesis that canonical IKK $\beta-N F-K B$ signalling drives tumour survival.

These results suggest that activation of the canonical NF-KB pathway is an important determinant of poor outcome in patients with invasive ductal breast cancer.

\section{INTRODUCTION}

Breast cancer is the most common female cancer in the UK and, despite earlier detection and improved treatments, remains the second most common cause of cancer death in women $[1,2]$. Therefore, it is clear that a further understanding of this disease process is required.
For many years an association between cancer and inflammation has been suspected and evidence has been gathered over the last decade to support this relationship [3, 4]. However, little is known about the signalling pathways that link these processes. The canonical mammalian Nuclear Factor kappa B (NF-kB) pathway regulates genes involved in many of the processes considered as hallmarks of cancer 
including inflammation, proliferation and apoptosis $[5,6]$. It is therefore not surprising that NF- $\kappa \mathrm{B}$ has been hypothesised to provide the link between inflammation and cancer [6-9].

Aberrant activity of various NF- $\mathrm{B}$ components has been observed in a number of solid tumours including colorectal [10] and prostate cancer [11-13]. In breast cancer, increased NF- $\mathrm{B}$ activity has been observed in rat mammary tumours compared to normal tissue [14] and numerous studies employing cell lines have reported an association with $\mathrm{NF}-\kappa \mathrm{B}$ activity and endocrine resistance [15]. In human breast cancer specimens, expression of the different NF- $\kappa$ B subunits have been observed $[14,15]$. Levels of phosphorylated $\mathrm{p} 65$ have been reported to correlate with HER2 expression, tumour size, grade and presence of metastases in a cohort of 57 patients [15] and high DNA binding activity of p50 was associated with decreased disease free survival in a cohort of 81 cases [17]. In a larger cohort of 208 cases, p65 expression was not associated with disease specific survival but was associated with luminal B subtype [16]. A clear consensus of the prognostic power of members of the canonical NF- $\kappa$ B pathway has not been reached.

Therefore the aims of the present study are to examine the relationship between key members of the canonical NF- $\kappa$ B pathway (IKK $\alpha$ and p65 (RelA)), local inflammatory infiltrate and survival in a cohort of patients with primary operable invasive ductal breast cancer.

\section{RESULTS}

A total of 376 patients who presented with invasive ductal breast cancer were included in the study. Seventy three patients had local or distant recurrences, the median follow-up of survivors was 164 months with 79 cancerassociated deaths and 79 non-cancer deaths. ER, PR, HER2 and Ki67 status was available for these patients allowing us to determine molecular subtype: $44 \%$ of patients had Luminal A disease (ER and PR positive, HER2 negative and low Ki67 <14\%), 21\% had Luminal B disease (ER, PR and HER2 positive or ER, PR and high Ki67 (>14\%)), 21\% had triple negative disease (ER, PR and HER2 negative) and 12\% with HER2 enriched disease (ER and PR negative, HER2 positive). We were unable to define molecular subtype in $2 \%$ of cases due to missing data.

Expression of IKK $\beta$ was observed in the cytoplasm and ranged from 0-275 weighed histoscore units (Supplementary Figure 1). P-p65 expression was observed in the cytoplasm ranging from 0-220 histoscore units and the nucleus ranging from 0-160 histoscore units (Supplementary Figure 2). Expression was split into tertiles, the first tertile was considered low expression and the second and third tertiles were grouped to provide a measure of moderate/high expression. Expression of IKK $\beta$ was not associated with cancer-specific survival (Figure 1A) $(\mathrm{P}=0.903)$, cytoplasmic p-p65 expression showed a non-significant trend towards shorter cancer-specific survival (Figure 1B, Table 2) $(\mathrm{P}=0.052)$ and nuclear $\mathrm{p}-\mathrm{p} 65$ expression showed a significant association with shorter cancer-specific survival (Figure 1C) $(\mathrm{P}=0.042)$. For nuclear p-p65 10 year cancer-specific survival was stratified from $84 \%$ to $71 \%(\mathrm{P}=0.022)$.

When patients were subdivided by molecular subtype, no significant associations were observed between IKK $\beta$ or cytoplasmic p-p65 expression in any of the molecular subtypes. When nuclear p-p65 was stratified by molecular subtype (Figure 1D-1G) the only subtype where the association with cancer-specific survival was upheld was in patients with Luminal $\mathrm{B}$ disease $(\mathrm{P}=0.018)$ (Figure 1E), 10 year cancer-specific survival was stratified from $83 \%$ to $57 \%(\mathrm{P}=0.006)$. A trend towards cancerspecific survival was observed in the triple negative subgroup, however due to low patient numbers this did not reach significance $(\mathrm{P}=0.120)$. No association between nuclear p-p65 and cancer-specific survival was observed in patients with Luminal A disease (Figure 1D) $(\mathrm{P}=0.972)$ or HER2 enriched disease (Figure $1 \mathrm{G})(\mathrm{P}=0.868)$.

As nuclear p-p65 was associated with cancerspecific survival, the relationship between this and tumour characteristics was subsequently examined (Table 1). High expression of nuclear p-p65 was associated with a high tumour grade $(\mathrm{P}=0.04)$ and tumour recurrence $(\mathrm{P}=0.008)$, but not tumour size, ER status, HER2 status or molecular subtype (Table 1). When associations with the tumour microenvironment were investigated, nuclear p-p65 expression was not significantly associated with tumour budding, T-lymphocytes or Klintrup-Makinen grade. However an association was observed with increasing tumour stromal percentage $(\mathrm{P}=0.033)$ (Table 1$)$.

When nuclear p-p65 was entered into a multivariate model using a backwards conditional method with clinicopathological parameters, nuclear p-p65 expression was not independently associated with cancer-specific survival in the full cohort (Table 2) but was independently associated with cancer-specific survival in Luminal B disease $(\mathrm{P}=0.019$, HR 1.95 (1.12-3.41)).

To examine the relationship of cancer-specific survival and total tumour cell p-p65, a cumulative prognostic score of cytoplasmic and nuclear p-p65 was examined. Patients with both low cytoplasmic and nuclear expression were classified as the low expression group and patients with either moderate/high cytoplasmic or nuclear expression were classified as the moderate/high expression group. Moderate/high expression of total tumour cell expression of p-p65 was significantly association with shorter cancer-specific survival (Figure $2 \mathrm{~A})(\mathrm{P}=0.025)$ and 10 year cancer-specific survival was stratified from $86 \%$ (low expression) to $75 \%$ (moderate/high expression) $(\mathrm{P}=0.006)$. When total tumour cell p-p65 was stratified by molecular subtype (Figure 2B-2E) the association between total tumour cell p-p65 and cancer-specific survival was lost in patients with Luminal A disease (Figure 2B) $(\mathrm{P}=0.712)$ (10 year survival, 90\% vrs $92 \%, \mathrm{P}=0.930)$ and in patients with HER2 enriched disease (Figure 2E) $(\mathrm{P}=0.992)$ (10 year survival, 67\% vrs $59 \%, \mathrm{P}=0.865)$. 
However a trend towards cancer-specific survival was observed in patients with Luminal B disease (Figure 2C) $(\mathrm{P}=0.142)$ (10 year survival, $78 \%$ vrs $55 \%, \mathrm{P}=0.091)$ and in triple negative disease (Figure 2D) $(\mathrm{P}=0.109)(10$ year survival, $90 \%$ vrs $66 \%, \mathrm{P}=0.071$ ), however due to low patient numbers these did not reach significance.

As total tumour cell p-p65 was associated with cancerspecific survival, the relationship between this prognostic model and tumour characteristics was subsequently examined (Table 3). High expression of total tumour cell expression of p-p65 was associated with a high tumour grade $(\mathrm{P}=0.01)$, ER positive disease $(\mathrm{P}=0.023)$, molecular subtype $(\mathrm{P}=0.005)$ and tumour recurrence $(\mathrm{P}=0.001)$. When associations with the tumour microenvironment were investigated, high total tumour cell expression was not significantly associated with tumour stromal percentage, tumour budding or T-lymphocytes. However an association was observed with local inflammatory cell infiltrate as assessed by Klintrup-Makinen grade $(\mathrm{P}=0.013)$ and density of $\mathrm{CD} 138^{+} \mathrm{B}$-lymphocytes $(\mathrm{P}=0.032)$.
When total tumour cell p-p65 was entered into a multivariate model using a backwards conditional method with clinicopathological parameters, total tumour cell p-p65 expression was independently associated with disease-free survival (HR 1.25(1.03-1.53), $\mathrm{P}=0.024$ ) (Table 2).

\section{Does IKK $\beta$ silencing impact on breast cancer cell phenotype?}

In the current study we report that activation of the canonical NF- $\kappa$ B pathway, measured by nuclear p-p65 expression and total tumour cell p-p65 expression, is associated with reduced cancer-specific survival. Therefore the next aim was to establish if inhibition of the canonical $\mathrm{NF}-\kappa \mathrm{B}$ pathway could offer a possible therapeutic option. MCF7 cells were chosen to represent ER positive breast tumours and MDA-MB-231 were chosen to represent ER negative breast tumours.

It was first established that the canonical NF- $\kappa \mathrm{B}$ pathway was inducible in both cell lines. This was
A

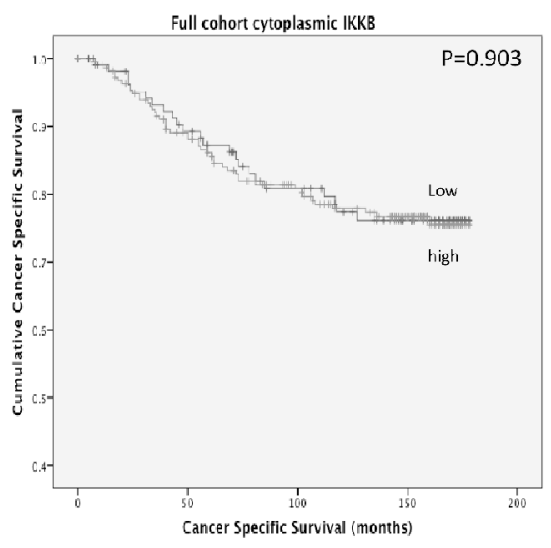

B

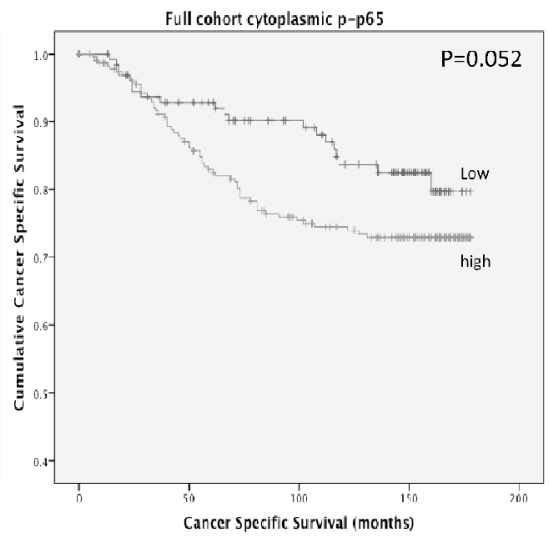

C

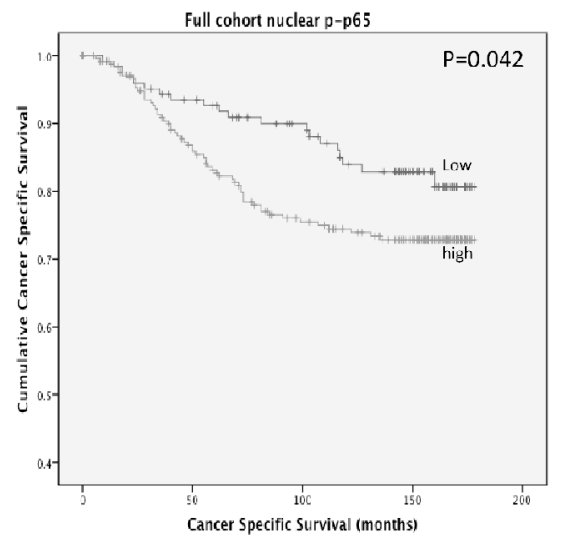

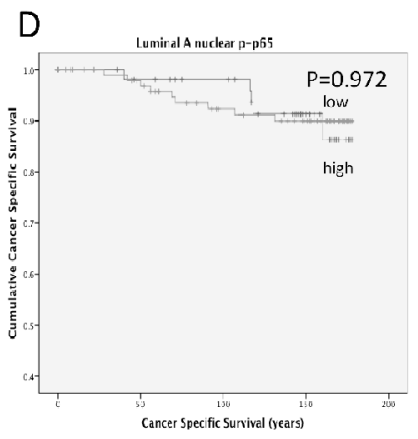
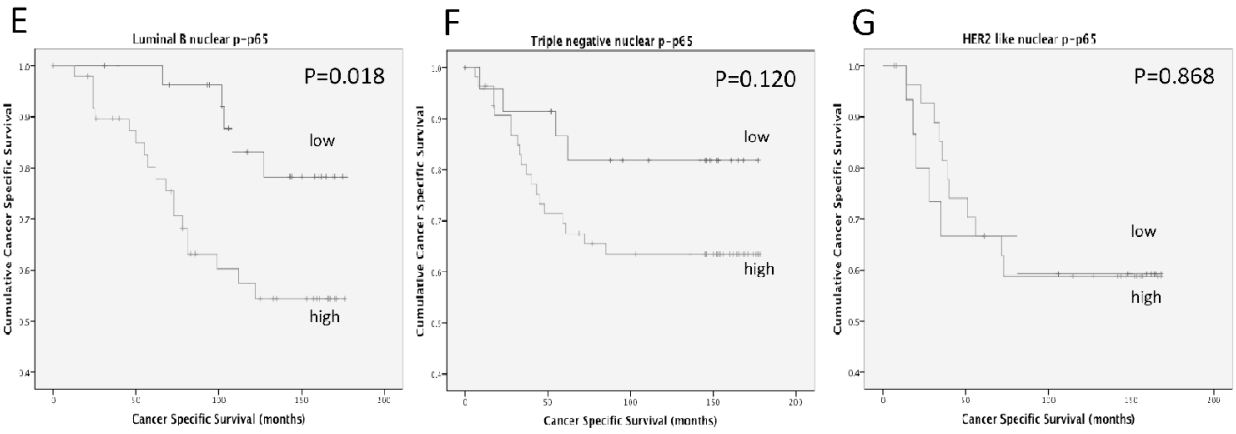

Figure 1: (A) shows the relationship between IKK $\beta$ expression and cancer-specific survival in patients with primary operable invasive ductal breast cancer $(\mathrm{P}=0.903)$. (B) shows the relationship between cytoplasmic p-p65 expression and cancer-specific survival in patients with primary operable invasive ductal breast cancer $(\mathrm{P}=0.052)$. (C) shows the relationship between nuclear p-p65 expression and cancerspecific survival in patients with invasive ductal breast cancer $(\mathrm{P}=0.042)$. (D) shows the relationship between nuclear p-p65 expression and cancer-specific survival in patients with Luminal A invasive ductal breast cancer $(\mathrm{P}=0.972)$. (E) shows the relationship between nuclear p-p65 expression and cancer-specific survival in patients with Luminal B invasive ductal breast cancer $(\mathrm{P}=0.018)$. (F) shows the relationship between nuclear p-p65 expression and cancer-specific survival in patients with triple negative invasive ductal breast cancer $(\mathrm{P}=0.120)$. $(\mathbf{G})$ shows the relationship between nuclear $\mathrm{p}-\mathrm{p} 65$ expression and cancer-specific survival in patients with HER2 enriched invasive ductal breast cancer $(\mathrm{P}=0.868)$. 
Table 1: The relationship between clinicopathological characteristics and nuclear p-p65 expression in patients with invasive ductal breast cancer

\begin{tabular}{|c|c|c|c|}
\hline Patients $n=376$ & $\begin{array}{c}\text { low } \\
(n=126)\end{array}$ & $\begin{array}{c}\text { high } \\
(\mathrm{n}=\mathbf{2 5 0})\end{array}$ & $P$ \\
\hline Age $(\leq 50 />50$ years $)$ & $36 / 90$ & $72 / 178$ & 0.963 \\
\hline Size $(\leq 20 / 21-50 />50 \mathrm{~mm})$ & $71 / 51 / 3$ & $142 / 102 / 6$ & 1.000 \\
\hline Grade (I / II / III) & $27 / 56 / 43$ & $40 / 97 / 113$ & 0.040 \\
\hline Involved lymph node (negative/positive) & $62 / 64$ & $134 / 111$ & 0.186 \\
\hline ER status (no/yes) & $44 / 82$ & $89 / 161$ & 0.495 \\
\hline PR status (no/yes) & $70 / 56$ & $133 / 117$ & 0.374 \\
\hline HER2 status (no/ yes) & $100 / 23$ & $200 / 49$ & 0.470 \\
\hline $\begin{array}{l}\text { Molecular subtype (Luminal A/Luminal B/triple } \\
\text { negative/HER2 enriched) }\end{array}$ & $54 / 29 / 25 / 15$ & $111 / 50 / 55 / 29$ & 0.897 \\
\hline Tumour necrosis (low/high) & $54 / 69$ & $105 / 140$ & 0.486 \\
\hline Lymph vessel invasion (no/yes) & $85 / 41$ & $160 / 89$ & 0.309 \\
\hline Blood vessel invasion (no/yes) & $108 / 18$ & $221 / 28$ & 0.246 \\
\hline Klintrup-Mäkinen grade (weak/strong) & $89 / 34$ & $174 / 71$ & 0.444 \\
\hline CD68+ (low/moderate/high) & $34 / 45 / 46$ & $61 / 95 / 93$ & 0.705 \\
\hline CD4+ (low/moderate/high) & $52 / 25 / 48$ & $99 / 58 / 92$ & 0.968 \\
\hline CD8+ (low/moderate/high) & $26 / 47 / 52$ & $73 / 92 / 84$ & 0.058 \\
\hline CD138+ (low/moderate/high) & $72 / 14 / 39$ & $129 / 35 / 85$ & 0.382 \\
\hline Angiogenesis (low/moderate/high) & $37 / 44 / 42$ & $78 / 81 / 82$ & 0.789 \\
\hline Tumour stroma percentage (low/high) & $82 / 42$ & $138 / 110$ & 0.033 \\
\hline Tumour budding (low/high) & $79 / 47$ & $162 / 87$ & 0.367 \\
\hline $\begin{array}{l}\text { Locoregional treatment } \\
\text { (lumpectomy+radiotherapy/mastectomy }+ \\
\text { radiotherapy) }\end{array}$ & $39 / 87$ & $97 / 153$ & 0.083 \\
\hline $\begin{array}{l}\text { Systemic treatment (hormonal/hormonal+ } \\
\text { chemotherapy/chemotherapy/ none) }\end{array}$ & $66 / 28 / 25 / 6$ & $125 / 51 / 58 / 11$ & 0.641 \\
\hline Recurrence (no recurrence/recurrence) & $104 / 20$ & $180 / 69$ & 0.008 \\
\hline
\end{tabular}

Bold indicates a significant association. Number of patients with missing data is not displayed, when values do not give a sum of $100 \%$ this is due to data being unavailable.

achieved by treating the cells with $\mathrm{TNF} \alpha$, which is known to stimulate the canonical pathway. In MCF7, ER positive breast cancer cells, TNF $\alpha$ exposure induced I $\mathrm{B} \alpha$ degradation and phosphorylation of $\mathrm{p} 65$ in a time dependent manner (Figure 3A). Following TNF $\alpha$ exposure, IкB $\alpha$ expression was reduced compared to control at 15 minutes and 30 minutes and phosphorylation of p65 (p-p65) was increased compared to control at 15 minutes and 30 minutes. Levels of p65 and IKK $\beta$ were unchanged by TNF $\alpha$ exposure.

In MDA-MB-231, ER negative breast cancer cells, TNF $\alpha$ exposure induced IкB $\alpha$ degradation but to a lesser extent than that observed in the MCF7 cells and no increase in phosphorylation of p65 (p-p65) was observed (Figure 3B). Following TNF $\alpha$ exposure, ІкB $\alpha$ expression was reduced compared to control at 15 minutes and 30 minutes. Levels of p65 and IKK $\beta$ were unchanged by TNF $\alpha$ exposure.

Having established that the canonical NF- $\mathrm{KB}$ pathway was active in both cell types, and inducible to a much greater extent in MCF7 cells, the next aim of the study was to assess the impact on cell viability by inhibiting the pathway via silencing of IKK $\beta$.

MCF7 and MDA-MB-231 cells were transfected with $200 \mathrm{nM}$ non-targeting (NT) siRNA or 200nM IKK $\beta$ siRNA, and 48 hours post treatment an apoptosis assay 
Table 2: The relationship between clinicopathological characteristics, nuclear p-p65 and cancer-specific survival in patients with invasive ductal breast cancer

\begin{tabular}{|c|c|c|c|c|c|c|}
\hline \multirow[b]{2}{*}{ Patients $(n=376)$} & \multicolumn{2}{|c|}{ Univariate analysis } & \multicolumn{2}{|c|}{$\begin{array}{l}\text { Multivariate analysis } \\
\text { Nuclear p-p65 }\end{array}$} & \multicolumn{2}{|c|}{$\begin{array}{l}\text { Multivariate analysis } \\
\text { Total tumour cell p-p65 }\end{array}$} \\
\hline & $\begin{array}{l}\text { Hazard ratio } \\
(95 \% \mathrm{CI})\end{array}$ & P value & $\begin{array}{l}\text { Hazard ratio } \\
(95 \% \mathrm{CI})\end{array}$ & P value & $\begin{array}{l}\text { Hazard ratio } \\
\text { (95\% CI) }\end{array}$ & $P$ value \\
\hline Age $(\leq 50 />50$ years $)$ & $1.33(0.812-2.24)$ & 0.248 & & & & \\
\hline Size $(\leq 20 / 21-50 />50 \mathrm{~mm})$ & $1.72(1.16-2.56)$ & 0.007 & & & & \\
\hline Grade (I / II / III) & $1.94(1.37-2.75)$ & $<0.001$ & & & & \\
\hline $\begin{array}{l}\text { Involved lymph node } \\
\text { (no/yes) }\end{array}$ & $3.34(2.04-5.47)$ & $<0.001$ & $2.39(1.40-4.07)$ & 0.001 & $2.13(1.23-3.68)$ & 0.007 \\
\hline ER status (no/yes) & $0.46(0.29-0.72)$ & 0.001 & & & & \\
\hline PR status (no/yes) & $0.37(0.22-0.61)$ & $<0.001$ & $0.43(0.25-0.730)$ & 0.002 & $0.44(0.25-0.74)$ & 0.002 \\
\hline HER2 status (no/ yes) & $2.15(1.33-3.48)$ & 0.002 & & & & \\
\hline Tumour necrosis (low/high) & $4.33(2.41-7.94)$ & $<0.001$ & $3.71(1.97-6.97)$ & $<0.001$ & $3.51(1.90-6.74)$ & $<0.001$ \\
\hline $\begin{array}{l}\text { Lymph vessel invasion } \\
\text { (no/yes) }\end{array}$ & $3.59(2.28-5.66)$ & $<0.001$ & & & & \\
\hline $\begin{array}{l}\text { Blood vessel invasion } \\
\text { (no/yes) }\end{array}$ & $3.01(1.79-5.06)$ & $<0.001$ & $2.42(1.38-4.24)$ & 0.002 & $2.19(1.23-3.90)$ & 0.007 \\
\hline $\begin{array}{l}\text { Klintrup-Mäkinen grade } \\
\text { (week/strong) }\end{array}$ & $1.32(0.82-2.13)$ & 0.249 & & & & \\
\hline CD68+ (low/moderate/high) & $0.78(0.59-1.04)$ & 0.093 & & & & \\
\hline CD4+ (low/moderate/high) & $1.00(0.782-1.28)$ & 0.938 & & & & \\
\hline CD8+ (low/moderate/high) & $0.62(0.46-0.82)$ & 0.001 & $0.54(0.40-0.74)$ & $<0.001$ & $0.54(0.40-0.72)$ & $<0.001$ \\
\hline $\begin{array}{l}\text { CD138+ (low/moderate/ } \\
\text { high) }\end{array}$ & $1.36(1.07-1.73)$ & 0.01 & 1.461.11-1.91) & 0.005 & $1.41(1.09-1.87)$ & 0.009 \\
\hline $\begin{array}{l}\text { Tumour stroma percentage } \\
\text { (low/high) }\end{array}$ & $1.26(1.44-3.54)$ & $<0.001$ & $2.12(1.32-3.41)$ & 0.002 & $2.10(1.30-3.38)$ & 0.002 \\
\hline Tumour budding (low/high) & $2.45(1.57-3.82)$ & $<0.001$ & $2.12(1.31-3.42)$ & 0.002 & $1.79(1.07-2.97)$ & 0.025 \\
\hline Nuclear p-p65 (low/high) & $1.29(1.00-1.67)$ & 0.045 & $1.31(0.99-1.73)$ & 0.057 & NA & NA \\
\hline $\begin{array}{l}\text { Total Tumour cell p-p65 } \\
\text { (both low/ one high) }\end{array}$ & $1.21(1.02-1.44)$ & 0.029 & NA & NA & $1.25(1.03-1.53)$ & 0.024 \\
\hline
\end{tabular}

or cell viability assay was performed (Figure 4A). A significant increase in apoptosis was observed in cells treated with siRNA to silence expression of IKK $\beta$ compared to the NT control (MCF7 cells, $\mathrm{P}<1.0 \times 10^{-6}$ and MDA-MB-231 cells, $\mathrm{P}=2 \times 10^{-4}$, Figure 4B) and a decrease in cell viability was observed in cells treated with siRNA to silence expression of IKK $\beta$ compared to the NT control (MCF7 cells, $\mathrm{P}=4.6 \times 10^{-5}$ and MDA-MB-231, $\mathrm{P}=0.002$, Figure $4 \mathrm{C}$ ). Cell viability was also measured using the xCELLigence machine, and cell index graphs following silencing in MCF7 and MDA-MB-231 cells (Figure 4D) plotted. Both cell types treated with siRNA to silence expression of IKK $\beta$ had reduced cell viability compared to both untreated control (C) and NT control (Figure 4D).

\section{DISCUSSION}

In the present study expression of key members of the canonical $\mathrm{NF}-\kappa \mathrm{B}$ pathway were investigated to establish if there was a link between the canonical NF-KB pathway, local inflammatory infiltrate and cancer-specific survival in a cohort of patients with primary operable invasive ductal breast cancer. Phosphorylation of p65 at serine 536 (p-p65) was employed as a marker of activation of the canonical NF- $\kappa \mathrm{B}$ pathway as it is important for transcriptional activation of the NF-KB dimer [26, 27]. High expression of p-p65 in the cytoplasm exhibited a non-significant trend towards a decrease in cancerspecific survival and high nuclear p-p65 was significantly 
associated with patient cancer-specific survival, recurrence and tumour grade. However no associations were made with nuclear p-p65 and inflammatory infiltrate, suggesting that this pathway is not responsible for regulating the local inflammatory response, but perhaps acting via an alternative mechanism such as proliferation.

Of additional interest was the observation that nuclear p-p65 was most strongly associated with cancerspecific survival in ER positive, Luminal B tumours. There are four main subtypes of breast cancer that are considered clinically relevant (Luminal A, Luminal B, HER2 enriched and triple negative). All subtypes have different molecular profiles and varied responses to endocrine therapy, HER2 targeted therapy and chemotherapy [3]. Differences in the biology of these subtypes are reflected in the results from this study, as activation of the NF- $\kappa \mathrm{B}$ pathway has diverging roles in the different subtypes. The present study demonstrates that the association of nuclear p-p65 expression with cancer-specific survival observed in the full cohort is negated in patients with ER positive Luminal A tumours but potentiated in patients with ER positive Luminal B tumours, indicating that this association is independent of ER status. This observation adds to the growing body of evidence that Luminal A and Luminal B breast cancers should be considered as different diseases and may require separate therapeutic approaches. Currently both these patient groups receive endocrine therapy, with Luminal B patients having a worse prognosis, which is associated with an increased rate of endocrine resistance. The increased rate of endocrine resistance has previously been attributed to the presence of HER2 in this subtype, providing an alternativesignalling pathway to escape the inhibitory effects of endocrine therapy. However, not all patients with Luminal $B$ disease exhibit overexpression of HER2 suggesting that the increased rate in endocrine recurrence in Luminal B disease might have been not be solely attributed to HER2 and might be due to an alternative mechanism in HER2 negative cases. Luminal B tumours are categorised as ER or PR positive tumours with either a high proliferation
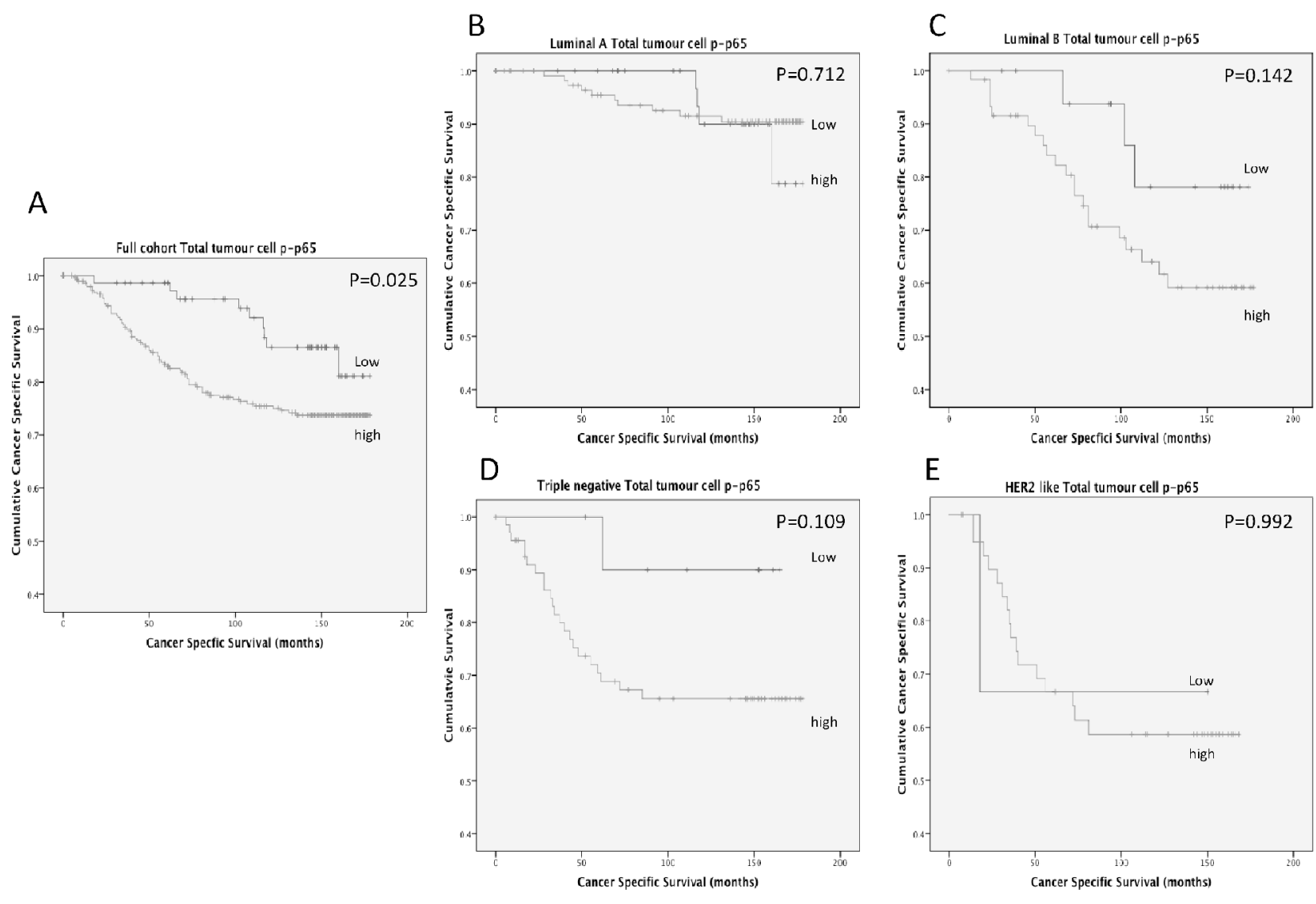

Figure 2: (A) shows the relationship between total tumour cell p-p65 expression and cancer-specific survival in patients with primary operable invasive ductal breast cancer $(\mathrm{P}=0.025)$. (B) shows the relationship between total tumour cell $\mathrm{p}$-p65 expression and cancer-specific survival in patients with Luminal A invasive ductal breast cancer $(\mathrm{P}=0.712)$. (C) shows the relationship between total tumour cell $\mathrm{p}$-p65 expression and cancer-specific survival in patients with Luminal B invasive ductal breast cancer $(\mathrm{P}=0.142)$. (D) shows the relationship between total tumour cell p-p65 expression and cancer-specific survival in patients with Triple negative invasive ductal breast cancer $(\mathrm{P}=0.109)$. (E) shows the relationship between total tumour cell p-p65 expression and cancer-specific survival in patients with HER2 enriched invasive ductal breast cancer $(\mathrm{P}=0.992)$. 
Table 3: The relationship between clinicopathological characteristics and total tumour cell pp65 expression in patients with invasive ductal breast cancer $(n=376)$

\begin{tabular}{|c|c|c|c|}
\hline & $\begin{array}{c}\text { low } \\
(n=74)\end{array}$ & $\begin{array}{c}\text { high } \\
(n=302)\end{array}$ & $\boldsymbol{P}$ \\
\hline Age $(\leq 50 />50$ years $)$ & $21 / 53$ & $87 / 215$ & 0.942 \\
\hline Size $(\leq 20 / 21-50 />50 \mathrm{~mm})$ & $40 / 31 / 2$ & $173 / 122 / 7$ & 0.682 \\
\hline Grade (I / II / III) & $18 / 35 / 21$ & $49 / 11 / 135$ & 0.010 \\
\hline Involved lymph node (negative/positive) & $37 / 37$ & $159 / 138$ & 0.339 \\
\hline ER status (no/yes) & $18 / 56$ & $115 / 187$ & 0.023 \\
\hline PR status (no/yes) & $38 / 36$ & $165 / 137$ & 0.612 \\
\hline Her2 status (no/ yes) & $62 / 9$ & $238 / 63$ & 0.075 \\
\hline $\begin{array}{l}\text { Molecular subtype (Luminal A/Luminal B/triple } \\
\text { negative/HER2 enriched) }\end{array}$ & $39 / 18 / 11 / 3$ & $126 / 61 / 69 / 41$ & 0.005 \\
\hline Tumour necrosis (low/high) & $32 / 40$ & $127 / 169$ & 0.813 \\
\hline Lymph vessel invasion (no/yes) & $51 / 23$ & $194 / 107$ & 0.470 \\
\hline Blood vessel invasion (no/yes) & $65 / 9$ & $264 / 37$ & 0.976 \\
\hline Klintrup-Mäkinen grade (weak/strong) & $60 / 12$ & 203/93 & 0.013 \\
\hline CD68+ (low/moderate/high) & $20 / 32 / 21$ & $75 / 108 / 118$ & 0.206 \\
\hline CD4+ (low/moderate/high) & $34 / 17 / 22$ & $117 / 66 / 118$ & 0.145 \\
\hline CD8+ (low/moderate/high) & $18 / 31 / 24$ & $81 / 108 / 112$ & 0.840 \\
\hline CD138+ (low/moderate/high) & $47 / 9 / 17$ & $154 / 40 / 107$ & 0.032 \\
\hline Tumour stroma percentage (low/high) & $46 / 27$ & $174 / 125$ & 0.453 \\
\hline Tumour budding (low/high) & $47 / 27$ & $194 / 107$ & 0.880 \\
\hline $\begin{array}{l}\text { Locoregional treatment } \\
\text { (lumpectomy+radiotherapy/mastectomy } \\
\text { +radiotherapy) }\end{array}$ & $24 / 50$ & $112 / 190$ & 0.456 \\
\hline $\begin{array}{l}\text { Systemic treatment (hormonal/hormonal+ } \\
\text { chemotherapy/chemotherapy/ none) }\end{array}$ & $40 / 19 / 11 / 3$ & $151 / 60 / 72 / 14$ & 0.244 \\
\hline Recurrence (no recurrence/recurrence) & $65 / 7$ & $219 / 82$ & 0.001 \\
\hline
\end{tabular}

Bold indicates a signicant association. Number of patients with missing data is not displayed, when values do not give a sum of $100 \%$ this is due to data being unavailable.
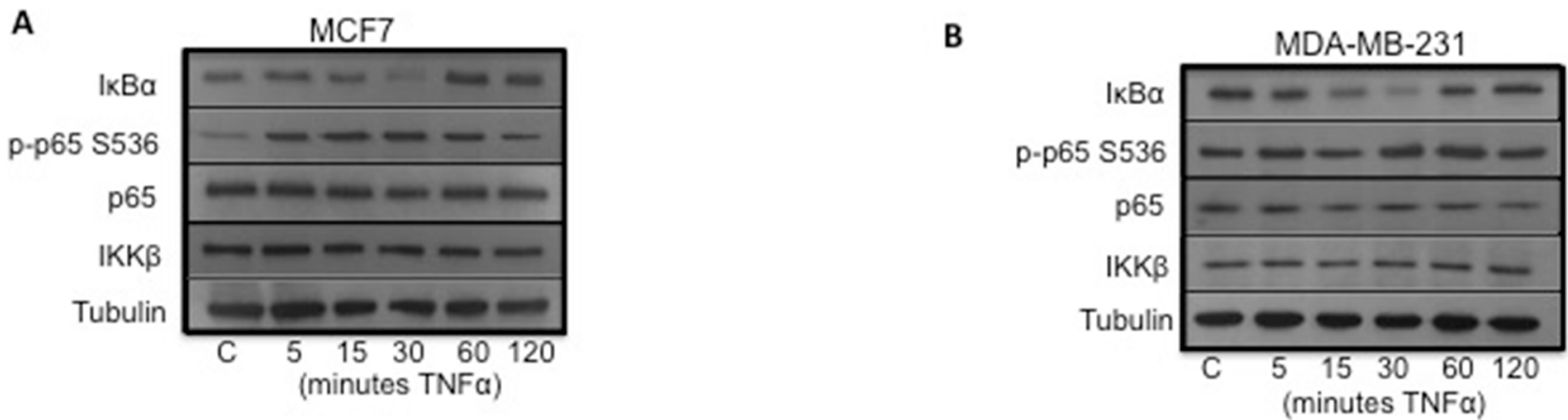

Figure 3: (A) shows Western blot and plots for MCF7 cells stimulated with TNFa. (B) shows Western blot and plots for MDA-MB-231 cells stimulated with TNF $\alpha$. 
rate $(\mathrm{Ki} 67>14 \%)$ or HER2 positivity. To investigate if the increased rate of recurrence observed in Luminal $B$ patients in the current study can be fully attributed to HER2 dependency and not NF- $\kappa \mathrm{B}$ pathway activation, patients with Luminal B tumours were further divided into those with HER2 positive tumours or high Ki67. The relationship with p-p65 and cancer-specific survival was maintained in highly proliferative tumours and not in those with HER2 positive tumours. Only very small numbers were available for analysis, so this observation should be confirmed in a larger cohort but does suggest that in the high Ki67 subgroup, activation of the NF- $\mathrm{B}$ pathway may also play a role in the increased rate of recurrence attributed to development of endocrine resistance. This in itself is not a novel observation as the NF- $\mathrm{B}$ pathway has previously been associated with development of endocrine resistance [28-30] and NF- $\kappa \mathrm{B}$ activity is enhanced in Tamoxifen resistant MCF7 cells compared to MCF7 Tamoxifen sensitive cells [28]. However, this is the first study to provide evidence suggesting that the NF$\kappa \mathrm{B}$ pathway may promote recurrence in Luminal B highly proliferative tumours, offering an alternative therapeutic strategy for patients with HER2 negative Luminal B disease. This approach may be employed in combination with endocrine treatment to delay development of endocrine resistance or as a therapeutic option following development of endocrine resistance.

To further investigate this hypothesis mechanistic studies examining the effect and most efficient method of suppressing activation of NF- $\kappa \mathrm{B}$ pathways are required. The present study investigated the impact of a reduction in IKK $\beta$ expression by siRNA transfection on MCF7 cell
A

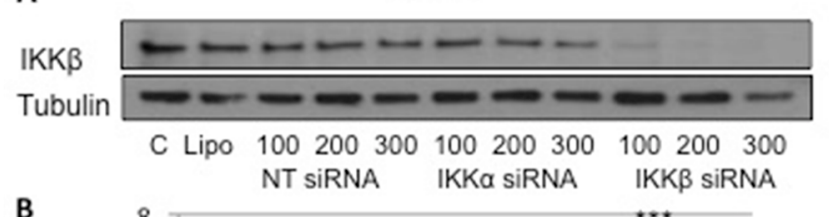

B

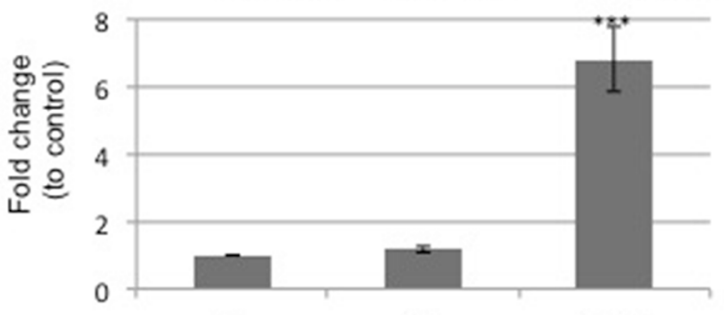

C

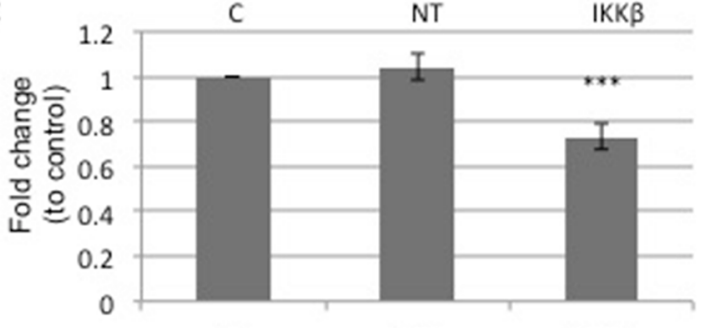

D

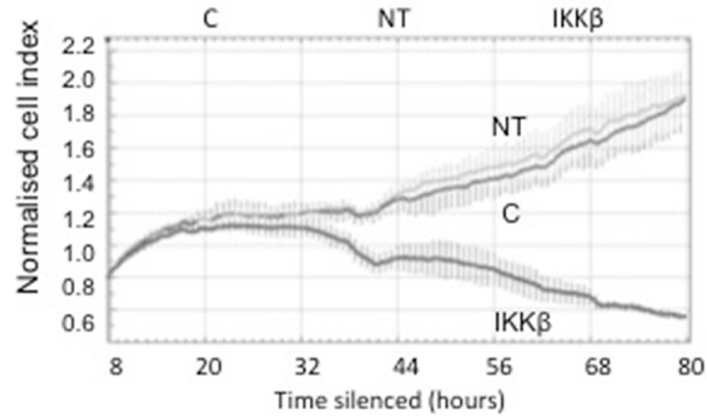

MDA-MB-231
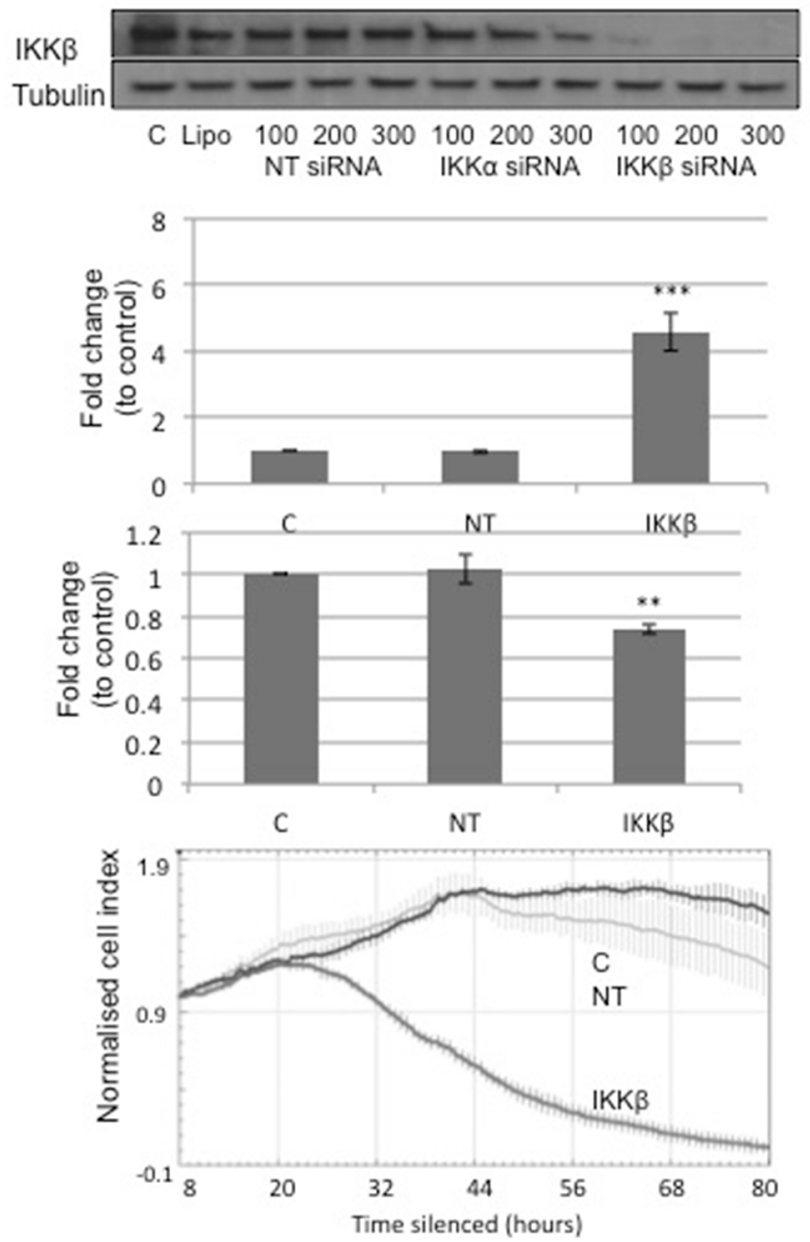

Figure 4: (A) shows Western blot for IKK $\beta$ and Tubulin expression in MCF7 ER positive cells, C is untreated cells, Lipo is cells treated only with lipofectamine, NT siRNA is cells treated with non-targeting siRNA, IKK $\alpha$ siRNA is cells treated with siRNA for IKK $\alpha$ and IKK $\beta$ siRNA is cells treated with siRNA for IKK $\beta$. Western blot shows that only siRNA for IKK $\beta$ lowers IKK $\beta$ expression. (B) shows plots for fold change in apoptosis levels in MCF7 cells and MDA-MB-231 cells treated with lipofectamine (C) non-targeting siRNA (NT) and IKK $\beta$ siRNA. (C) shows plots for fold change in cell viability levels in MCF-7 cells and MDA-MB 231 cells treated with lipofectamine (C), nontargeting siRNA (NT) and IKK $\beta$ siRNA. (D) shows xCELLigence cell index plots for MCF7 cells and MDA-MB 231 cells treated with lipofectamine (C), non-targeting siRNA (NT) and IKK $\beta$ siRNA. 
viability, using various methods, including assessment of apoptosis using an ELISA, viability using a WST-1 assay, real time growth and viability using xCELLigence cell index. All modes of assessment demonstrated that reduction in IKK $\beta$ expression resulted in a decrease of cell viability. These results taken together with our clinical cohort results suggest that it may be beneficial to block NF- $\kappa \mathrm{B}$ activity in ER positive Luminal B patients in combination with endocrine therapy or following development of endocrine resistance.

Although the effect we observed was potentiated in patients with ER positive, Luminal B disease, a trend towards significance was also observed in patients with ER, PR, HER2 negative (triple negative) disease but not ER negative, HER2 enriched disease. Although the trend did not reach significance in patients with triple negative disease, 10 year cancer-specific survival was stratified from $82 \%$ to $53 \%$. Significance was possibly not met due to the study being underpowered to observe differences in this subtype. This is also in concordance with the in vitro work in the current study as high levels of phosphorylation of p65 was observed in ER negative MDA-MB-231 cells and suppression of the pathway via a reduction in IKK $\beta$ expression by siRNA resulted in decreased cell viability. This is in line with the literature where high levels of NF-KB activity have been reported in ER-negative tumours [28].

In addition to investigating associations between nuclear p-p65 expression and patient outcome measures, a cumulative prognostic score combining both cytoplasmic and nuclear p-p65 was examined. Using this cumulative prognostic score the current study observed that total cell expression was a stronger predictor of cancer-specific survival compared to nuclear alone and was independently associated with cancer-specific survival when combined with clinico-pathological parameters. In addition to the increased prognostic power observed for total tumour cell p-p65 compared to nuclear p-p65, total tumour cell p-p65 was associated with more measurements of the local inflammatory response. Nuclear p-p65 was only associated with tumour grade, tumour stroma percentage, recurrence and cancer-specific survival, in comparison to total tumour cell p-p65 being associated with tumour grade, ER status, molecular subtype, Klintrup-Makinen grade, CD138+ cells, recurrence and cancer-specific survival. This suggests that examining total cell p-p65 expression results in a more accurate, robust measurement of activated NF-KB in the tumour cell prior to or following nuclear translocation. Therefore total tumour cell p-p65 may be employed as a possible prognostic marker, or predictive marker for therapies targeting NF-kB. When stratified by molecular subtype, although not reaching significance, a trend was observed between reduced cancer-specific survival and total tumour cell p-p65 in the Luminal B and triple negative subtypes, in line with that observed for nuclear p-p65.
In summary, results from the present study demonstrate a significant role of the canonical NF- $\kappa B$ pathway in the progression of breast cancer, which appears to be greater in Luminal B and triple negative subtypes. Selective novel compounds targeting NF-кB pathway may offer a promising therapeutic approach. Furthermore, clinical trials should be designed incorporating predictive biomarkers to ensure that only subtypes known to respond to NF- $\kappa \mathrm{B}$ intervention would receive treatment to maximise benefit and minimise unwanted toxicities.

\section{MATERIALS AND METHODS}

\section{Patient cohorts}

The TMA included tumour tissue samples from 376 breast cancer patients presenting with invasive ductal breast cancer between 1995 and 1998 in the West of Scotland (at Glasgow Royal Infirmary, Glasgow Western Infirmary and Stobhill Hospital). Clinico-pathological data available included age, tumour grade, tumour size, lymph node status, therapy, ER, PR and HER2 status and Ki67 proliferation index. Information on inflammatory infiltrate and tumour microenvironment had previously been established for the cohort [18-23]. H\&Es slides were employed to assess tumour stroma percentage (TSP) and Klintrup-Makinen as previously reported [19-21]. Lymph and blood vessel invasion (LVI and BVI, respectively) were assessed, using IHC staining with the lymphatic endothelial marker D2-40 and vascular endothelial marker Factor VIII as previously described [31].

Tissue microarrays (TMAs) made from formalinfixed paraffin-embedded tissue (FFPE) blocks which were retrieved from pathology archives were already available for this retrospective study. Tumour rich areas selected for construction of the TMA were identified by a consultant pathologist. Ethical approval for the use of this tissue was granted by the research Ethics Committee of the North Glasgow University Hospitals NHS Trust (NHS GG\&C rec no 10/50704/60). In accordance with REMARK criteria, the markers examined, study objectives and hypothesis was described. Patient clinicopathological characteristics have been described, specimen characteristics provided, IHC methods and antibody specificity confirmed. Biomarkers have been shown in relation to prognostic variables and univariate and multivariate analysis applied.

\section{Immunohistochemistry}

Immunohistochemistry (IHC) was performed to assess protein levels of members of the NF- $\mathrm{KB}$ pathways; IKK $\beta$ and phosphorylated p65 subunit at serine 536 of NF- $\kappa \mathrm{B}(\mathrm{p}-\mathrm{p} 65)$. TMAs were cut into $2.5 \mu \mathrm{m}$ thick sections, tissue was dewaxed by immersion in xylene and rehydrated through a series of graded alcohols. Heat 
induced antigen retrieval was performed in a solution of either citrate buffer pH6 (IKK $\beta$ ) or Tris EDTA buffer pH9 (p-p65). Tissue was then incubated in 3\% hydrogen peroxide before non-specific binding was blocked by incubation in either 5\% normal horse serum solution (Vector Laboratories; IKK $\beta$ ) or $1 \mathrm{x}$ caesin solution (Vector Laboratories; p-p65,). Slides were then incubated in primary antibody overnight at $4^{\circ} \mathrm{C}$ (IKK $\beta$, p-p65). Antibodies were diluted to optimal concentration in antibody diluent (Dako). Primary antibodies for anti-IKK $\beta$ was ab32135, Abcam at 1:500 and for anti p-p65 was ab28856, Abcam at 1:25. Staining was developed using EnVision $^{\mathrm{TM}}$ (Dako) and 3,3'-diaminobenzidine (DAB; Vector Laboratories). Harris Haematoxylin counterstaining was performed and tissue was dehydrated and mounted using DPX.

Stained TMA sections were scanned using a Hamamatsu NanoZoomer (Welwyn Garden City, Hertfordshire, UK) at x20 magnification and visualization was carried out using Slidepath Digital Image Hub, version 4.0.1 (Slidepath, Leica Biosystems, Milton Keynes, UK). Protein expression was assessed using the weighted histoscore method [LB], with a second independent observer [JE] scoring $10 \%$ of cores and the interclass correlation coefficient (ICCC) calculated to ensure no observer bias [24]. P-p65 cytoplasmic and nuclear expression within the cytoplasm and nucleus were calculated separately.

\section{Cell culture}

MCF7 and MDA-MB-231 breast cancer cells were cultured in Dulbecco's Modified Eagle Medium (DMEM) (Life Technologies) with 10\% Fetal Bovine Serum (FBS) (Sigma-Aldrich), 10 Units/ml Penicillin/ Streptomycin (Life Technologies) and 1x GlutaMAX ${ }^{\mathrm{TM}}$ (Life Technologies) in $5 \% \mathrm{CO}_{2}$ at $37^{\circ} \mathrm{C}$.

\section{Ligand exposure}

Cells were seeded in 12 well plates at $1 \times 10^{5}$ cells per well and once $70 \%$ confluence was reached, cells were rendered quiescent by serum deprivation for 24 hours before being stimulated by exposure to $20 \mathrm{ng} / \mathrm{ml} \mathrm{TNF} \alpha$ (Sigma-Aldrich) at a range of time points ( 5 minutes, 15 minutes, 30 minutes, 60 minutes and 120 minutes).

\section{Western blotting}

At end of incubations/exposure to agents, cells were lysed in pre-heated Laemmli's sample buffer, dispered by repeating passing through a $21 \mathrm{G}$ needle and heated at $100^{\circ} \mathrm{C}$ for $5 \mathrm{~min}$ prior to analysis. SDS-Polyacrylamide Gel Electrophoresis (SDS-PAGE) was performed to separate proteins, which were then transferred to nitrocellulose membranes by electrophoretic blotting in wet conditions. Non-specific binding then blocked in 3\% (w/v) BSA in NaTT buffer and membranes were incubated overnight, either at room temperature or $4^{\circ} \mathrm{C}$, in primary antibody specific to the target protein diluted to optimal concentration in NaTT buffer containing $0.3 \%(\mathrm{w} / \mathrm{v})$ BSA. Antibodies and dilutions used were as follows: p65 (1:10000, sc-8008, Santa Cruz), p-p65 (1:1000, \#3031, Cell Signaling), IкB $\alpha$ (1:7500, \#1242, Cell Signaling), $\operatorname{IKK} \beta(1: 2500$, ab32135, Abcam) and $\beta$-tubulin (at 1:5000, ab21058, Abcam).

Membranes were incubated in secondary HRPconjugated antibody (either rabbit or mouse, depending on primary antibody) diluted 1:10000. Enhanced chemiluminescence (ECL) reagent was used to detect presence of the antibody and X-ray films developed using an X-OMAT machine (Kodak) or the G:Box imaging system (SynGene).

\section{Silencing}

Cells were transfected with ON-TARGETplus siRNA (Thermo Scientific) targeting IKK $\beta$ (IKBKB, \#J-003503-13). In order to confirm the observed effects were due to the loss of IKK $\beta$ and not the transfection procedure, cells were treated with all reagents (lipofectamine ${ }^{\circledR}$ diluted in Opti-MEM $®$ ) but no siRNA as a control (C) and were transfected with non-targeting sequence as a control (non-targeting \#1, \#D001810-01-20) (NT). IKK $\beta$ siRNA at $100 \mathrm{nM}$ for all, $200 \mathrm{~nm}$ and $300 \mathrm{~nm}$ was delivered to the cells using lipofectamine $\mathbb{R}$ RNAiMAX (Life Technologies) diluted in Opti-MEM ${ }^{\circledR}$ (Life Technologies) and media was replaced with normal DMEM containing 10\% (v/v) FCS after 6 hours. Following 48 hours silencing, a Western blot was performed to establish the extent of silencing (Figure 4), extent of IKK $\alpha$ silencing was also investigated [32]. From these results a concentration of $200 \mathrm{nM}$ IKK $\beta$ siRNA was chosen as the concentrations used in all future experiments for both cell lines.

\section{Apoptosis and cell viability assays}

After knockdown of mRNA expression, cells were plated for apoptosis or cell viability assays. Apoptosis levels were assessed using a Cell Death Detection enzymelinked immunosorbent assay kit (Roche) and for cell viability using the water-soluble tetrazolium salt (WST-1) reagent (Roche). Cells were seeded in a 96 well plate at a density of $5 \times 10^{3}$ cells/well in $100 \mu \mathrm{L}$ of standard culture medium. Once a confluency of $60-70 \%$ was reached cells were exposed to siRNA for 48 hours and the assays then performed following manufacturer's instructions. Assays were performed in triplicate and error bars representing standard deviation added to graphs. Fold change was compared to control.

\section{Cell viability via $x$ CELLigence}

The xCELLigence machine (ACEA Biosciences, San Diego) was used to display cell growth and viability in 
real time following silencing of IKK $\beta$. With this method, measurements are continuously sent to the computer, allowing for real time growth curves to be plotted using "Cell Index" which represents the number and viability of the cells [25]. Cells were seeded in a 96 well E-plate ${ }^{\mathrm{TM}}$ (ACEA Biosciences, San Diego) at $3 \times 10^{3}$ cells/well with $200 \mu$ l of media in each well, grown for two days to ensure log phase of growth before treatment with siRNA and after 72 hours graphs showing cell index over time were drawn.

\section{Statistical analysis}

Statistics was performed using IBM SPSS version 21. Kaplan-Meier curves were constructed for cancerspecific survival, the log rank test was employed to compare high and low expression. Hazard ratios were calculated using Cox regression with 95\% confidence intervals. Cox regression multivariate analysis was also performed with the inclusion of known predictive factors. Inter-relationships between variables were assessed using contingency tables with the chi-squared test for trend as appropriate. Values of $\mathrm{P}<0.05$ were considered statistically significant.

Statistical analysis for apoptosis and cell viability assays was performed using a two-way ANOVA with Bonferroni correction and Dunnett's test. P values were considered significant if $\mathrm{P}<0.05$ and highly significant if $\mathrm{P}<0.001$.

\section{ACKNOWLEDGMENTS}

We gratefully acknowledge Clare Orange, who provided technical assistance. We also thank the NHS Biorepository for providing us with tissue samples.

\section{CONFLICTS OF INTEREST}

No conflict of interest to be declared.

\section{REFERENCES}

1. CRUK. (2014). Breast cancer incidence statistics. Available: http://www.cancerresearchuk.org/cancerinfo/ cancerstats/ types/breast/incidence/ [Accessed 23/06/2014].

2. CRUK. (2014). Breast cancer mortality statistics. Available: http://www.cancerresearchuk.org/cancerinfo/ cancerstats/ types/breast/mortality/ [Accessed 23/06/2014].

3. Eccles SA, Aboagye EO, Ali S, Anderson AS, Armes J, Berditchevski F, Blaydes JP, Brennan K, Brown NJ, Bryant HE, Bundred NJ, Burchell JM, Campbell AM, et al. Critical research gaps and translational priorities for the successful prevention and treatment of breast cancer. Breast Cancer Res. 2013; 15:R92.

4. Lee HJ, Kim JY, Park IA, Song IH, Yu JH, Ahn JH, Gong G. Prognostic Significance of Tumor-Infiltrating Lymphocytes and the Tertiary Lymphoid Structures in HER2-Positive Breast Cancer Treated With Adjuvant Trastuzumab. Am J Clin Pathol. 2015; 144:278-88.

5. Häcker H, Karin M. Regulation and function of IKK and IKK-related kinases. Sci STKE. 2006; 2006:re13.

6. Perkins ND, Gilmore TD. Good cop, bad cop: the different faces of NF-kappaB. Cell Death Differ. 2006; 13:759-72.

7. Raposo TP, Beirão BC, Pang LY, Queiroga FL, Argyle DJ. Inflammation and cancer: till death tears them apart. Vet J. 2015; 205:161-74.

8. Karin M. NF-kappaB as a critical link between inflammation and cancer. Cold Spring Harb Perspect Biol. 2009; 1:a000141.

9. Thu YM, Richmond A. NF- $\mathrm{B}$ B inducing kinase: a key regulator in the immune system and in cancer. Cytokine Growth Factor Rev. 2010; 21:213-26.

10. Kojima M, Morisaki T, Sasaki N, Nakano K, Mibu R, Tanaka M, Katano M. Increased nuclear factor-kB activation in human colorectal carcinoma and its correlation with tumor progression. Anticancer Res. 2004; 24:675-81.

11. Lindholm PF, Bub J, Kaul S, Shidham VB, Kajdacsy-Balla A. The role of constitutive NF-kappaB activity in PC-3 human prostate cancer cell invasive behavior. Clin Exp Metastasis. 2000; 18:471-79.

12. Gasparian AV, Yao YJ, Kowalczyk D, Lyakh LA, Karseladze A, Slaga TJ, Budunova IV. The role of IKK in constitutive activation of NF-kappaB transcription factor in prostate carcinoma cells. J Cell Sci. 2002; 115:141-51.

13. McCall P, Bennett L, Ahmad I, Mackenzie LM, Forbes IW, Leung HY, Sansom OJ, Orange C, Seywright M, Underwood MA, Edwards J. NFкB signalling is upregulated in a subset of castrate-resistant prostate cancer patients and correlates with disease progression. Br J Cancer. 2012; 107:1554-63.

14. Sovak MA, Bellas RE, Kim DW, Zanieski GJ, Rogers AE, Traish AM, Sonenshein GE. Aberrant nuclear factorkappaB/Rel expression and the pathogenesis of breast cancer. J Clin Invest. 1997; 100:2952-60.

15. Zhou Y, Eppenberger-Castori S, Eppenberger U, Benz CC. The NFkappaB pathway and endocrine-resistant breast cancer. Endocr Relat Cancer. 2005 (Suppl 1); 12:S37-46.

16. Sarkar DK, Jana D, Patil PS, Chaudhari KS, Chattopadhyay BK, Chikkala BR, Mandal S, Chowdhary P. Role of NF- $\kappa$ B as a Prognostic Marker in Breast Cancer : A Pilot Study in Indian Patients. Indian J Surg Oncol. 2013; 4:242-47.

17. Rajković-Molek K, Mustać E, Hadžisejdić I, Jonjić N. The prognostic importance of nuclear factor $\kappa \mathrm{B}$ and hypoxiainducible factor $1 \alpha$ in relation to the breast cancer subtype and the overall survival. Appl Immunohistochem Mol Morphol. 2014; 22:464-70.

18. Gujam FJ, Going JJ, Mohammed ZM, Orange C, Edwards $\mathrm{J}$, McMillan DC. Immunohistochemical detection improves the prognostic value of lymphatic and blood vessel invasion in primary ductal breast cancer. BMC Cancer. 2014; 14:676. 
19. Gujam FJ, Edwards J, Mohammed ZM, Going JJ, McMillan DC. The relationship between the tumour stroma percentage, clinicopathological characteristics and outcome in patients with operable ductal breast cancer. Br J Cancer. 2014; 111:157-65.

20. Mohammed ZM, McMillan DC, Edwards J, Mallon E, Doughty JC, Orange C, Going JJ. The relationship between lymphovascular invasion and angiogenesis, hormone receptors, cell proliferation and survival in patients with primary operable invasive ductal breast cancer. BMC Clin Pathol. 2013; 13:31.

21. Mohammed ZM, Going JJ, Edwards J, Elsberger B, McMillan DC. The relationship between lymphocyte subsets and clinico-pathological determinants of survival in patients with primary operable invasive ductal breast cancer. Br J Cancer. 2013; 109:1676-84.

22. Mohammed ZM, Orange C, McMillan DC, Mallon E, Doughty JC, Edwards J, Going JJ. Comparison of visual and automated assessment of microvessel density and their impact on outcome in primary operable invasive ductal breast cancer. Hum Pathol. 2013; 44:1688-95.

23. Mohammed ZM, Going JJ, Edwards J, Elsberger B, Doughty JC, McMillan DC. The relationship between components of tumour inflammatory cell infiltrate and clinicopathological factors and survival in patients with primary operable invasive ductal breast cancer. Br J Cancer. 2012; 107:864-73.

24. Kirkegaard T, Edwards J, Tovey S, McGlynn LM, Krishna SN, Mukherjee R, Tam L, Munro AF, Dunne B, Bartlett JM. Observer variation in immunohistochemical analysis of protein expression, time for a change? Histopathology. 2006; 48:787-94.

25. Ke N, Wang X, Xu X, Abassi YA. The xCELLigence system for real-time and label-free monitoring of cell viability. Methods Mol Biol. 2011; 740:33-43.
26. Sakurai H, Suzuki S, Kawasaki N, Nakano H, Okazaki T, Chino A, Doi T, Saiki I. Tumor necrosis factor-alphainduced IKK phosphorylation of NF-kappaB p65 on serine 536 is mediated through the TRAF2, TRAF5, and TAK1 signaling pathway. J Biol Chem. 2003; 278:36916-23.

27. Baker AF, Dragovich T, Ihle NT, Williams R, FenoglioPreiser C, Powis G. Stability of phosphoprotein as a biological marker of tumor signaling. Clin Cancer Res. 2005; 11:4338-40.

28. Nakshatri H, Bhat-Nakshatri P, Martin DA, Goulet RJ Jr, Sledge GW Jr. Constitutive activation of NF-kappaB during progression of breast cancer to hormoneindependent growth. Mol Cell Biol. 1997; 17:3629-39.

29. Cogswell PC, Guttridge DC, Funkhouser WK, Baldwin AS Jr. Selective activation of NF-kappa B subunits in human breast cancer: potential roles for NF-kappa B2/p52 and for Bcl-3. Oncogene. 2000; 19:1123-31.

30. Zhou Y, Yau C, Gray JW, Chew K, Dairkee SH, Moore DH, Eppenberger U, Eppenberger-Castori S, Benz CC. Enhanced NF kappa B and AP-1 transcriptional activity associated with antiestrogen resistant breast cancer. BMC Cancer. 2007; 7:59.

31. Gujam FJ, Going JJ, Edwards J, Mohammed ZM, McMillan DC. The role of lymphatic and blood vessel invasion in predicting survival and methods of detection in patients with primary operable breast cancer. Crit Rev Oncol Hematol. 2014; 89:231-41.

32. Bennett L, Quinn J, McCall P, Mallon EA, Horgan PG, McMillan DC, Paul A, Edwards J. High IKKa expression is associated with reduced time to recurrence and cancer specific survival in oestrogen receptor (ER)-positive breast cancer. Int J Cancer. 2017; 140: 1633-1644. 